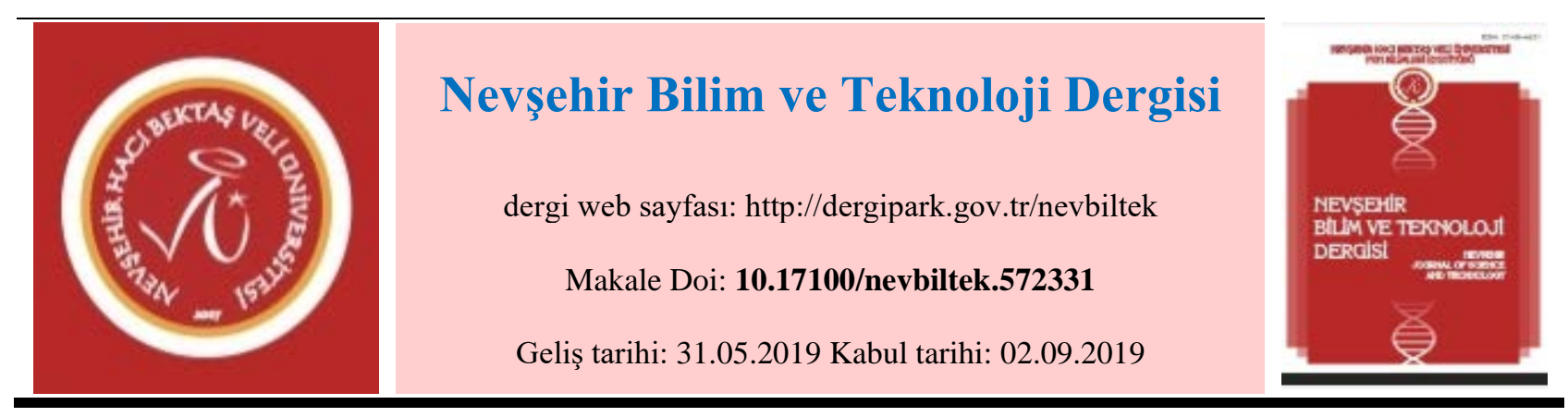

\title{
İç Mimarlık Lisans Eğitimi, Dersler ve Sürdürülebilirlik
}

\author{
Serkan Sipahi $^{1,}$, Alper Torun ${ }^{2}$ \\ ${ }^{1}$ Atatürk Üniversitesi, Mimarlık ve Tasarım Fakültesi, Iç Mimarlık Bölümü, Erzurum, Türkiye \\ ORCID ID: 0000-0002-5684-8671 \\ ${ }^{2}$ Atatürk Üniversitesi, Mimarlık ve Tasarım Fakültesi, İç Mimarlık Bölümü, Erzurum, Türkiye \\ ORCID ID: 0000-0002-6069-6551
}

\begin{abstract}
Öz
Günümüzde endüstrinin her alanında yeri olan sürdürülebilirlik kavramı, inşaat sektöründe de oldukça dikkat çekici bir konudur. Özellikle bina yaşam döngüsünün çevresel etkileri düşünüldüğünde sürdürülebilirlik kavramının yapı sektörü için önemi daha iyi anlaşılmaktadır. Binalarda sürdürülebilirlik konusu irdelendiği zaman ise bina iç mekanlarında sürdürülebilirliğin; bina çevresi ve bina kabuğu kadar önemli bir yere sahip olduğu görülmektedir. Bununla birlikte bu değişimlerin iç mimarlık eğitimine ne kadar yansıdığı bir tartışma konusudur. Tasarım görüşleri, malzeme, yapım teknikleri gibi konular iç mimarlık eğitimine zaman içerisine eklenmekle birlikte; sürdürülebilirlik konusunun ne kadar dahil edildiği ülkemiz ve tüm dünya için bir soru işaretidir. Bu çalışmada sürdürülebilirlik konusunun iç mimarlık lisans programlarına dahil edilmesi hususunda, kavramın derslere yansıması üzerine bir araştırma yapılmıştır. Örneklem grubu olarak farklı bakış açılarına sahip Türkiye'de bulunan eğitim kurumları alınmıştır. Bu nedenle ülkemizde iç mimarlık lisans programlarından 5 farklı program, örneklem grubu olarak belirlenmiştir. Örneklem grubunda yer alan iç mimarlık lisans programlarının dersleri, ders bilgi paketleri üzerinden irdelenmiştir. İrdeleme 2 aşamadan oluşmaktadır. İlk aşamada ders bilgi paketlerinde yer alan amaç ve içerik başlıkları irdelenmiş; sürdürülebilirlik kavramının etkili olmayacağı düşünülen türk dili, ingilizce gibi alan dışı dersler ile teknik resim, temel sanat eğitimi gibi temel eğitim dersleri kapsam dıșı bırakılmıştır. İkinci aşamada ise ders öğrenme çıktıları ve haftalık ayrıntılı ders içerikleri incelenerek, derslerin sürdürülebilirlik kavramıyla ilişsilendirilip ilişkilendirilmediği ve ne şekilde ilişkilendirildiği konuları tartışılmıştır. Söz konusu ilişkilendirmenin analizi için LEED ve BREEAM sertifikasyon sistemlerine ait iç mekanı etkileyen kriterler kullanılmıştır. Sonuç olarak endüstrinin her alanında önemli bir yeri olan sürdürülebilirlik kavramının iç mekan tasarımı kapsamındaki karşıllı̆ına dikkat çekilmiştir. Bina ölçeğinde uygulayıcı olacak tasarımcı adaylarının, sürdürülebilirlik kavramı ile eğitim sürecinde ne kadar etkileşimde olduğu ortaya konulmuştur.
\end{abstract}

Anahtar Kelimeler: Sürdürülebilirlik, Eğitim, İç Mimarlık Eğitimi, Sürdürülebilirlik ve İç Mimarlık

\section{Interior Architecture Undergraduate Education, Courses And Sustainability}

\begin{abstract}
Today, the concept of sustainability, which has a place in all aspects of the industry, is quite remarkable in the construction sector. Especially considering the environmental impacts of the building life cycle, the importance of sustainability for the building industry is better understood. When the sustainability of buildings is examined, it is seen that sustainability in the interior of buildings is as important as the building environment and the building shell. However, it is a matter of debate on how these changes are reflected in interior architecture education. While the issues such as design ideas, materials and construction techniques are added to the interior architecture education over time, sustainability is a question mark for our country and for the whole world. In this study, a survey was carried out on how and how the concept relates with which courses is included in the undergraduate programs of interior Architecture. The research was conducted through the universities of Turkey. As a sample group, educational institutions with different perspectives have been taken. For this reason, the faculty, in which the interior architecture undergraduate programs are located in Turkey, has been designated as the sample group of 5 different programs by paying attention to the issues such as the date of its establishment, State-Foundation university status, and the name of the Department. The courses of the interior architecture undergraduate programs in the sample group are examined through the course information packages. Examination consists of 2 stages. In the first stage of the course, the subjects of the purpose and content included in the information packages were examined and the basic education courses such as Turkish language, English, technical drawing, basic art education, which are thought to be ineffective in the concept of sustainability were excluded
\end{abstract}


In the second stage, the course learning outcomes and weekly detailed course contents were examined, whether the courses are associated with the concept of sustainability and how they relate to the subjects were discussed. For the analysis of the association in question, the criteria affecting the internal space of LEED and BREEAM certification systems were used. As a result, it is pointed out that the concept of sustainability, which has an important place in all areas of industry, is covered by interior design. It has been demonstrated how much designer candidates will interact with the concept of sustainability in the education process.

Keywords: Sustainability, Education, Interior Architecture Education, Sustainability and Interior Architecture

\section{Giriş}

Gelişen teknoloji ile birlikte önceleri genel isimler ile anılan bilim dalları uzmanlaşma ihtiyacı ile birlikte ayrışarak yeni bilim dallarının oluşturulmasına neden olmuştur. Zaman içerisinde uzmanlaşma ihtiyacının ortaya çıktığı bilim dallarından bir tanesinin de mimarlık alanı olduğu söylenebilir. İç mimarlık eğitimi de mimarlık alanı içerisinde oluşturulmuş uzmanlaşma gerektiren bir bilim dalıdır.

Sürdürülebilirlik ise gelişen teknoloji ile birlikte ortaya çıkan çevresel sorunların çözümü için oluşturulmuş bir kavramdır. Özellikle 70’li yıllardan itibaren giderek artan çevresel sorunlar ile birlikte her alanda olduğu gibi mimarlıkta da çevresel sorunlara karşı sürdürülebilir çözümler geliştirilmektedir.

Sürdürülebilir çözümlerin geliştirildiği sektörlerin bir tanesi olan mimarlık ve inşaat sektörü için sürdürülebilirlik oldukça önemlidir. Binalarda sürdürülebilirlik konusunun önemi; Avrupa Birliği ülkelerinde, toplam enerji kullanımının \%40’tan fazlasının, CO2 emisyonunun \%30’unun ve sentetik atıkların \%40’ının bina sektöründen kaynaklanması ile açıklanabilir [1],[2].

Mimarlıkta sürdürülebilir çözümlerin geliştirilmesi ile yeşil bina kavramı ortaya çıkmıştır. Bugün sürdürülebilir, ekolojik, çevre dostu vb. pek çok isim altında karşımıza çıkan yeşil binalar, yapının arazi seçiminden başlayarak yaşam döngüsü çerçevesinde değerlendirilerek, bütüncül bir anlayışla, sosyal ve çevresel sorumluluk anlayışıyla tasarlanan, iklim verilerine ve o yere özgü koşullara uygun, ihtiyacı kadar tüketen, yenilenebilir enerji kaynaklarına yönelmiş, doğal ve atık üretmeyen malzemelerin kullanıldığı, ekosistemlere duyarlı ve sürdürülebilir yapılar olarak tanımlanmaktadırlar [5].

Yeşil binalar ile birlikte binaların sürdürülebilirliklerinin denetlenmesi amacı ile bazı sertifikasyon sistemleri ortaya konulmuştur. Sertifika sistemleri, genel ve geçerli ölçme standartları oluşturarak yeşil binayı tanımlamak, bütünsel bir bina tasarım yöntemi geliştirmek, yapı sektöründe çevresel liderlik tanımak, yeşil rekabeti teşvik etmek, yeşil binanın yararları konusunda tüketici bilincini arttırarak bina pazarını dönüştürmeyi amaçlamaktadır [6].

Bina sertifikasyon sistemleri ve yeşil bina kavramları dışında mimarlık eğitiminde de sürdürülebilirlik kavramı üzerine bazı araştırmalar yapılmış; bu araştırmalar sonucunda mimarlık eğitiminde sürdürülebilirlik bağlamında yapılması gereken değişiklikler, Uluslararası Mimarlar Birliği (UIA) ve Birleşmiş Milletler Eğitim Bilim ve Kültür Örgütü (UNESCO) tarafından 1996 yılında hazırlanan Mimarlık Eğitimi Şartı'nda da belirtilmiştir. Yayımlanan bu şarta göre, gelecekteki yaşam çevrelerini oluşturmak için benimsenmesi gereken hedefler şu şekilde sıralanmıştır.

- Yerleşim yerlerindeki bütün insanlar için, insanlığa yaraşır bir yaşam kalitesi;

- İnsanların, sosyal, kültürel ve estetik gereksinimlerine saygılı bir teknik uygulama; yapılı çevrenin ekolojiye duyarlı ve sürdürülebilir gelişimi;

- Herkesin kendi malı ve sorumluluğu olarak görüp değer verdiği bir mimari, şeklindedir [3].

Her eğitim alanında olduğu gibi mimarlık eğitimi de çağın gereksinimleri ile değişmektedir. Çağın ihtiyaç ve imkanları doğrultusunda değişen mimarlık alanına bakıldığı zaman 20 yıl öncesi ile günümüzde bazı farklılıklar bulunmaktadır. $\mathrm{Bu}$ farklılıklardan en belirgin olanı bilgisayar destekli tasarımın günümüzde gerekliliği nedeni ile mimarlık eğitiminin her alanında kendisine yer bulmasıdır. Sürdürülebilirlik konusunda da belirlenen hedeflerin uygulanması hususunda yeşil bina sertifikasyon sistemleri baz alınarak yapının içi, dışı ve çevresi ile bir bütün olması nedeni ile mimarlık, iç mimarlık, şehir ve bölge planlaması, peyzaj mimarlığı gibi alanların eğitim aşamalarında bazı değişikliklere gidilmesi gerekmektedir. Bu değişikliklerin ise ülkemiz üniversitelerinde yeterli yapılıp yapılmadığı bir tartışma konusudur. Bu çalışmada, yeşil bina sertifikasyon sistemleri üzerinden sürdürülebilirlik kavramının iç mimarlık eğitimi üzerinde ne kadar değişikliğe neden olduğu ülkemiz üniversiteleri iç mimarlık bölümleri üzerinden irdelenecektir.

\section{Materyal ve Metot}

Çalışmada sürdürülebilirlik kavramının iç mimarlık lisans programlarında yer alan derslere yansıması üzerine bir araştırma yapılmıştır. Bu şekilde geleceğin tasarımcı adaylarını yetiştiren kurumlar incelenerek sürdürülebilirlik 
konusunun iç mimarlık mesleki eğitimindeki yeri irdelenmişrtir. Çalışmanın örneklem grubunu Türkiye’de İç Mimarlık eğitimi konusunda farklı bakış açılarına sahip beş eğitim kurumu oluşturmaktadır. Bu kurumlar:

- $\quad$ Marmara Üniversitesi Güzel Sanatlar Fakültesi İç Mimarlık Bölümü,

- Hacettepe Üniversitesi Güzel Sanatlar Fakültesi İç Mimarlık ve Çevre Tasarımı Bölümü,

- $\quad$ Eskişehir Teknik Üniversitesi (eski adıyla Anadolu Üni.) Mimarlık ve Tasarım Fakültesi İç Mimarlık

Bölümü,

- İstanbul Kültür Üniversitesi Sanat ve Tasarım Fakültesi İç Mimarlık ve Çevre Tasarımı Bölümü

- İstanbul Teknik Üniversitesi Mimarlık Fakültesi İç Mimarlık Bölümü

Örneklem grubunda yer alan iç mimarlık lisans programlarının dersleri, ders bilgi paketleri üzerinden irdelenmiştir. İrdeleme iki aşamadan oluşmaktadır:

İlk aşamada ders bilgi paketlerinde yer alan "amaç" ve "içerik” başlıkları irdelenmiş; sürdürülebilirlik kavramı ile ilişki kurulamayacak türk dili, ingilizce gibi alan dışı dersler ile teknik resim, temel sanat eğitimi gibi temel eğitim dersleri kapsam dışı bırakılmıştır. Bu aşamada ayrıca sürdürülebilirliği doğrudan konu alan seçmeli derslere ulaşılmıştır. Sürdürülebilirliği doğrudan konu alan bu dersler Tablo 1'de detayları açıklanan kriterlere göre bilgi paketlerinde yer alan "öğrenme çıktıları" ve "haftalık detaylı içerkler” göz önünde bulundurularak incelenmiştir. Söz konusu inceleme için LEED ve BREEAM sertifikasyon sistemlerine ait iç mekanı etkileyen kriterler kullanılmıştır. Bu kriterler (Tablo 1): "Enerji, kirlilik, malzeme, atık yönetimi, su, sağlık ve konfor" şeklinde sıralanmıştır [4].

İkinci aşamada sürdürülebilirlik kavramıyla ilişki kurulabilecek diğer derslerin “ders öğrenme çıktıları" ve "haftalık ayrıntılı ders içerikleri” incelenmiştir. Derslerin sürdürülebilirlik kavramıyla ilişkilendirilip ilişkilendirilmediği veya ne şekilde ilişkilendirildiği yukarıda bahsedilen kriterler kapsamında tartışılmıştır. İç mimarlık eğitiminin tasarım temelli bir modele dayanması ve teorik içerikli tüm derslerin aslında studio derslerini desteklemek amacında olması nedeniyle [8] diğer derslerin de bu bağlamda incelenmesi tartışmaya katkı sağlamıştır. Sonuçta öğrenciler edindikleri bilgileri uygulamanın ön planda olduğu bu derslerde pratiğe dökerek deneyim kazanmaktadır. Tasarım temelli çoğu mesleki eğitim sisteminde olduğu gibi iç mimarlık eğitiminde de dersler teorik bilgilerin, tasarım süreciyle ilişkilendirilmiş uygulamalı derslerle pekiştirileceği şekilde birbirini destekleyen ve tamamlayan yapıdadır [7]. Bu yüzden sürdürülebilirlik kavramının derslere yansıması incelenirken özellikle uygulamalı dersler de gözden geçirilmiş, bu şekilde sürdürülebilirlik kavramının eğitim sistemi içindeki yeri daha geniş kapsamda sorgulanmıştır.

Böylece artık endüstrinin birçok alanında önemli bir yeri olan sürdürülebilirlik kavramının iç mekan tasarımı kapsamındaki karşılığına dikkat çekilmiş ve bina ölçeğinde uygulayıcı olacak tasarımcı adaylarının, eğitim sürecinde sürdürülebilirlik kavramı ile ne kadar etkileşimde olduğu tartışılmıştır. 
Tablo 1. İç Mekanda sürdürülebilirliğin değerlendirme kriterleri ve kıstasları [4].

\begin{tabular}{|c|c|}
\hline KRITTERLER & KISTASLAR \\
\hline Enerji & $\begin{array}{l}\text { Enerji tasarruf sistemleri } \\
\text { Yapı tasarımı ve enerji tasarrufu } \\
\text { Temel iklimlendirme yönetimi } \\
\text { Yenilenebilir enerji kullanımı } \\
\text { Düşük karbon teknolojileri kullanımı } \\
\text { Enerji alt ölçümleri } \\
\text { Yapı sistemlerinde enerji verimliliği }\end{array}$ \\
\hline Kirlilik & $\begin{array}{l}\text { Soğutucu ekipman kullanımı } \\
\text { Atık yönetimi } \\
\text { Azot oksit salınımı }\end{array}$ \\
\hline Malzeme & $\begin{array}{l}\text { Geri dönüşüm } \\
\text { Dönüştürülmüş malzemelerin kullanımı } \\
\text { Sorumlu kaynak yönetimi } \\
\text { Malzemelerin yaşam döngüsünün çevreye etkisi } \\
\text { Malzemelerin sağlamlığ } 1\end{array}$ \\
\hline Atık yönetimi & $\begin{array}{l}\text { Dönüştürülmüş inşaat malzemesi kullanımı } \\
\text { Atık yapıları } \\
\text { Geri dönüşüm olanakları }\end{array}$ \\
\hline $\mathrm{Su}$ & $\begin{array}{l}\text { Su tüketimi } \\
\text { Verimli ekipman kullanımı } \\
\text { Suyun geri dönüştürülmesi }\end{array}$ \\
\hline Sağlık ve konfor & $\begin{array}{l}\text { Gün 1şığı kullanımı } \\
\text { Hijyen } \\
\text { Güvenlik } \\
\text { Ses ve gürültü konforu } \\
\text { Sigara duman kontrolü } \\
\text { Isısal konfor } \\
\text { Akustik } \\
\text { İç mekân hava kalitesi } \\
\text { Ișı düzeyleri }\end{array}$ \\
\hline
\end{tabular}

\section{Bulgular}

Örneklem grubunu oluşturan kurumların ders bilgi paketlerinde yer alan "amaç" ve "içerik" başlıklarının irdelendiği ilk aşamada; sürdürülebilirlik kavramı ile ilişki kurulamayacak alan dışı dersler ve temel eğitim dersleri elenmiştir. Bu aşamada sürdürülebilirliği doğrudan konu alan bazı derslere ulaşılmış ve bu dersler iç mekanı etkileyen "Enerji, kirlilik, malzeme, atık yönetimi, su, sağlık ve konfor" kriterlerine göre incelenmiştir (Tablo 2). Derslerin sürdürülebilirlik kavramı ile ne şekilde ilişkilendirildiği bu kriterler kapsamında tartışılmıştır.

MÜ İç Mimarlık lisans programında "Sürdürülebilir Tasarım İlkeleri" adıyla bir addet, HÜ İç Mimarlık ve Çevre Tasarımı lisans programında "Sürdürülebilir Tasarım" ve "Sürdürülebilir Kent ve Mekan" adlarıyla iki adet, İKÜ İç Mimarlık ve Çevre Tasarımı lisans programında İç "Mimarlıkta Sürdürülebilir Tasarım" ve "Enerji Etkin Tasarım Yaklaşımı" adlarıyla iki adet, İTÜ İç Mimarlık lisans programında ise "Sustainability in Interior Architecture" adıyla bir adet derse ulaşılmıştır. Eskişehir Tek. Üni. İç Mimarlık lisans programında ise doğrudan sürdürülebilirliği konu alan herhangi bir derse ulaşılamamıştır (Tablo 2). 
Tablo 2. Örneklem grubunu oluşturan İç Mimarlık Lisans Programlarında doğrudan sürdürülebilirliği konu alan derslere ait bilgi paketlerinin [9], [10], [11], [12], [13] incelenmesi

\begin{tabular}{|c|c|c|c|c|c|c|c|}
\hline Üniversite / Fakülte / Bölüm & Ders Adı & 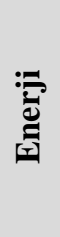 & 彦 & 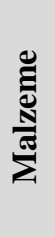 & 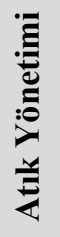 & के & 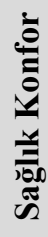 \\
\hline $\begin{array}{l}\text { MÜ Güzel Sanatlar Fakültesi } \\
\text { İç Mimarlık Bölümü }\end{array}$ & $\begin{array}{c}\text { Sürdürülebilir Tasarım İlkeleri (seçmeli } \\
\text { ders) }\end{array}$ & $\checkmark$ & $\sim$ & $\checkmark$ & $\sim$ & $\sim$ & $\sim$ \\
\hline \multirow{2}{*}{$\begin{array}{c}\text { HÜ Güzel Sanatlar Fakültesi } \\
\text { İç Mimarlık ve Çevre Tasarımı } \\
\text { Böl. }\end{array}$} & $\begin{array}{l}\text { Sürdürülebilir Tasarım } \\
\text { (seçmeli ders) }\end{array}$ & $\checkmark$ & $\sim$ & $\checkmark$ & $\sim$ & $\sim$ & $\checkmark$ \\
\hline & $\begin{array}{l}\text { Sürdürülebilir Kent ve Mekan Tasarımı } \\
\text { (seçmeli ders) }\end{array}$ & $\sim$ & $\sim$ & $\checkmark$ & $\sim$ & $\sim$ & $\sim$ \\
\hline $\begin{array}{l}\text { Eskişehir Tek. Üni. } \\
\text { Mimarlık ve Tasarım Fakültesi } \\
\text { İç Mimarlık Bölümü }\end{array}$ & $\begin{array}{c}\text { (sürdürülebilirliği doğrudan konu alan } \\
\text { zorunlu veya seçmeli bir ders } \\
\text { bulunmamaktadır) }\end{array}$ & $\mathrm{X}$ & $\mathrm{X}$ & $\mathrm{X}$ & $\mathrm{X}$ & $\mathrm{X}$ & $\mathrm{X}$ \\
\hline \multirow{2}{*}{$\begin{array}{c}\text { İKÜ Sanat ve Tasarım Fakültesi } \\
\text { İç Mimarlık ve Çevre Tasarımı } \\
\text { Böl. }\end{array}$} & $\begin{array}{l}\text { İç Mimarlıkta Sürdürülebilir Tasarım } \\
\text { (seçmeli ders) }\end{array}$ & $\checkmark$ & $\sim$ & $\sim$ & $\sim$ & $\sim$ & $\sim$ \\
\hline & $\begin{array}{l}\text { Enerji Etkin Tasarım Yaklaşımı } \\
\text { (seçmeli ders) }\end{array}$ & $\checkmark$ & $\sim$ & $\sim$ & $\sim$ & $\sim$ & $\sim$ \\
\hline $\begin{array}{l}\text { İTÜ Mimarlık Fakültesi } \\
\text { İç Mimarlık Bölümü }\end{array}$ & $\begin{array}{l}\text { Sustainability in Interior Architecture } \\
\text { (seçmeli ders) }\end{array}$ & $\checkmark$ & $\checkmark$ & $\checkmark$ & $\checkmark$ & $\checkmark$ & $\checkmark$ \\
\hline \multicolumn{8}{|c|}{$\sqrt{ }$ : Destekleniyor, $\quad$ : K1smen Destekleniyor, X: Desteklenmiyor } \\
\hline
\end{tabular}

Ders bilgi paketlerinin incelenmesi sonucunda sadece İTÜ İç Mimarlık lisans programında yer alan dersin söz konusu kriterlerin hepsini desteklediği görülmektedir. "Sustainability in Interior Architecture" adlı dersin bilgi paketinde dersin kapsadığı konular için şu ifadeler kullanılmıştır: “...yapı/yapımın çevreye, insan performansı ve sağlığına etkisi: yerleşim, enerji, su, malzemeler, atıklar, toplum ve yaşam kalitesi; iç mekan kalitesi bağlamında gereksinim duyulan fizyolojik özellikler: iklimsel görsel konfor, ergonomi, duyumsal alg1; geri dönüşüm ve yeniden kullanım; sürdürülebilir tasarım ve değerlendirme; tasarım sertifika programları ve değerlendirme araçları.” [14].

Bir insanın hayatı boyunca en çok vakit geçirdiği alanın "iç mekan” olduğu düşünüldüğünde sürdürülebilirlik gibi her geçen gün önemini artıran bir konunun iç mekan tasarımı eğitiminde söz konusu kriterlerin hepsini kapsayacak şekilde yer alması oldukça önemlidir. Bu bağlamda tartışılabilecek konu bu derslerin seçmeli ders formatında olması dolayısıyla öğrencilerin sadece bir kısmına hitap ediyor olmasıdır.

Öte yandan örneklem grubundaki diğer kurumlarda doğrudan sürdürülebilirliği konu alan derslerin LEED ve BREEAM sertifikasyon sistemlerine ait iç mekanı etkileyen kriterlerin hepsini desteklemediği görülmektedir. Özellikle "Kirlilik, Atık Yönetimi ve Su” kriterleri göz önünde bulunduruşlduğunda; ders bilgi paketlerinde bu kriterlere doğrudan gönderme yapacak herhangi bir ifadenin yer almadığı görülmüştür. Detaylı haftalık ders içerikleri de incelendiğinde söz konusu kriterlerin tek tek ifade edilmediği görülmektedir. Fakat bu derslerde konu "Sürdürülebilir tasarımın birleşenleri" veya "Sürdürülebilirlik ilkeleri” şeklinde daha geniş kapsamda ele alınmıştır. Dolayısıyla ders içeriğinin teorik olarak bu kriterkleri kısmen içerdiği anlaşılmaktadır. Derslerin genel anlamda enerji ve malzeme konusuna odaklandığı görülmektedir.

$\mathrm{Bu}$ derslerin hepsi seçmeli ders formatındadır ve öğrencilere sürdürülebilirilik konusunda farkındalık kazandırmayı amaçlamaktadır. İç Mimarlık lisans eğitimi kapsamında doğrudan sürdürülebilirliği konu alan derslerin LEED ve BREEAM sertifikasyon sistemlerine ait iç mekanı etkileyen kriterlerin hepsini destekleyecek şekilde düzenlenmesi amaca daha uygun bir yaklaşım olacaktır. Ayrıca teorik bilgilerin pekiştirilmesi için sürdürülebilirlik kavramının, tasarım süreciyle şekillenmiş diğer derslerle ilişkilendirilmesi faydalı olacaktır. Bu doğrultuda sürdürülebilirlik kavramıyla ilişki kurulabilecek diğer derslerin "ders öğrenme çıktıları" ve "haftalık ayrıntılı ders 
içerikleri” incelenmiştir. Derslerin sürdürülebilirlik kavramıyla ilişkilendirilip ilişkilendirilmediği veya ne şekilde ilişkilendirildiği aynı kriterler kapsamında tartışılmıştır (Tablo 3,4,5,6,7).

Derslerin bilgi paketlerinde yer alan "amaç" ve "içerik" başlıkları irdelendiği ilk aşamada, alan dışı ve temel eğitim dersleri kapsam dışında bırakılmıştır. Bu şekilde birinci ve ikinci yarıyıllarda verilen hiçbir dersin sürdürülebilirlik kavramıyla ilişki kurulabilecek nitelikte olmadığı saptanmıştır. Marmara Üniversitesi İç Mimarlık lisans programında yer alan derslerin sürdürülebilirlik kapsamında incelenmesi ile ilgili detaylar Tablo 3 ’te verilmiştir.

Tablo 3. MÜ İç Mimarlık lisans programında sürdürülebilirlikle ilişki kurulabilecek ders bilgi paketlerinin [9] incelenmesi

\begin{tabular}{|c|c|c|c|c|c|c|c|}
\hline & $\begin{array}{c}\text { Marmara Üniversitesi } \\
\text { İç Mimarlık Lisans Programı } \\
\text { DERS ADI }\end{array}$ & : & 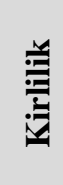 & 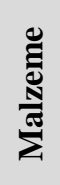 & 曾 & के & 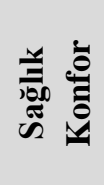 \\
\hline & Stüdyo İç Mekan I, II, III, IV, V, Diploma Proj. & $\mathrm{X}$ & $\mathrm{X}$ & $\sim$ & $\mathrm{X}$ & $\mathrm{X}$ & $\sim$ \\
\hline & $\begin{array}{l}\text { Stüdyo Mobilya I, II } \\
\end{array}$ & $\mathrm{X}$ & $\mathrm{X}$ & $\mathrm{X}$ & $\mathrm{X}$ & $\mathrm{X}$ & $\mathrm{X}$ \\
\hline d & Mobilya Konstrüksiyon I, II, III, IV & $\mathrm{X}$ & $\mathrm{X}$ & $\mathrm{X}$ & $\mathrm{X}$ & $\mathrm{X}$ & $\mathrm{X}$ \\
\hline$\overline{\bar{g}}$ & Mimarlık Yapı Bilgisi I, II & $\mathrm{X}$ & $\mathrm{X}$ & $\sim$ & $\mathrm{X}$ & $\mathrm{X}$ & $\sim$ \\
\hline$\stackrel{\theta}{=}$ & Malzeme & $\mathrm{X}$ & $\mathrm{X}$ & $\sim$ & $\mathrm{X}$ & $\mathrm{X}$ & $\mathrm{X}$ \\
\hline $\bar{\Xi}$ & Tasarım Teorisi & $\mathrm{X}$ & $\mathrm{X}$ & $\mathrm{X}$ & $\mathrm{X}$ & $\mathrm{X}$ & $\mathrm{X}$ \\
\hline กั & Tasarımda Uygulama Pratikleri I, II & $\mathrm{X}$ & $\mathrm{X}$ & $\mathrm{X}$ & $\mathrm{X}$ & $\mathrm{X}$ & $\sim$ \\
\hline$\dot{m}$ & Stüdyo Serbest Mobilya I, II, III & $\mathrm{X}$ & $\mathrm{X}$ & $\mathrm{X}$ & $\mathrm{X}$ & $\mathrm{X}$ & $\mathrm{X}$ \\
\hline$\stackrel{\mathrm{A}}{0}$ & Aydınlatma & $\mathrm{X}$ & $\mathrm{X}$ & $\mathrm{X}$ & $\mathrm{X}$ & $\mathrm{X}$ & $\sim$ \\
\hline $\bar{\Xi}$ & Atölye Uygulamaları & $\mathrm{X}$ & $\mathrm{X}$ & $\sim$ & $\mathrm{X}$ & $\mathrm{X}$ & $\mathrm{X}$ \\
\hline 岕 & Sürdürülebilir Tasarım İlkeleri & $\checkmark$ & $\sim$ & $\checkmark$ & $\sim$ & $\sim$ & $\sim$ \\
\hline
\end{tabular}

MÜ İç Mimarlık lisans programında üçüncü yarıyıldan başlayıp son yarıyıla kadar devam eden "Stüdyo İç Mekan” dersleri bilgi paketlerine göre; "insan-yapı-çevre ilişkileri ve işlev-form-renk-malzeme faktörlerinin tanımı ve birbirleriyle ilişkileri" üzerine yoğunlaşmış uygulamalı dersleri ifade eder. İç Mimarlık lisans eğitimi genel anlamda, edinilen tüm bilgilerin bu derslerde pratiğe dökülerek bir iç mekan tasarımı projesi şeklinde çıktı olarak teslim edildiği modele dayanmaktadır. Bilgi paketlerine göre MÜ İç Mimarlık lisans programında yer alan "Stüdyo İç Mekan" dersleri "Malzeme ve Sağlık-Konfor" kriterlerini kısmen desteklediği ifade edilebilir. Fakat diğer kriterleri desteklemediği görülmektedir [9]. "Stüdyo Mobilya ve Stüdyo Serbest Mobilya" dersleri de benzer bir şekilde donatı ölçeğindeki proje sürecini ifade etmektedir. Bilgi paketlerine göre bu dersler söz konusu kriterlerin hiçbirini desteklememektedir.

"Mobilya Konstrüksiyon, Yapı bilgisi ve malzeme" dersleri bilgi paketlerine göre farklı ölçeklerde "işlevform-malzeme faktörlerinin önemi" üzerine yoğunlaşmıştır. Fakat malzemelerin yaşam döngüsü, çevreye etkisi ya da sorumlu kaynak yönetimi gibi konulara değinilmemiştir. "Tasarım Teorisi” dersi, tasarımın günlük yaşama etkileri ve gerekliliği, değişen ekolojik dengeler, teknoloji v.b. konularda tasarımcının sorumlulukları, tasarım sonrası denetim gibi konuları işlemektedir. Fakat konuların sürdürülebilirlikle ilişkisi kurulmamıştır. "Tasarımda Uygulama Pratikleri” dersi bilgi paketinde "sağlık ve güvenlik standartları" konusundan bahsedilse de konu "Hijyen, konfor, hava kalitesi" bağlamında ele alınmamıştır. Seçmeli derslerden "Aydınlatma" dersi ışık kaynakları ve düzeyleri ile ilgili konuları kapsasa da konu; doğal kaynaklar, gün ışığı, konfor veya sağlık kapsamında ele alınmamıştır. "Atölye Uygulamaları" dersi, bilgi paketine göre malzeme, renk, doku, maliyet, v.b. konuları kapsamaktadır. Ders bilgi paketinde malzemenin yaşam döngüsü içindeki aşamaların bir kısmına gönderme yapılsa da konu sürdürülebilirlik kapsamında ele alınmamıştır. Bu derste de enerji, kirlilik, atık yönetimi, su ya da sağlık-konfor kriterlerini destekleyen herhangi bir ifadeye rastlanmamıştır.

Sonuç olarak MÜ İç Mimarlık lisans propgramında yer alan "Sürdürülebilir Tasarım İlkeleri” dersi dışında sürdürülebilirlikle ilişki kurulabilecek dersler incelendiğinde, derslerin hiçbir kriteri doğrudan desteklemediği görülmüştür. Ders bilgi paketlerine göre "Enerji, Malzeme ve Sağlık-konfor" kriterleri bazı dersler tarafından kısmen desteklense de "Kirlilik ve Su" kriterleri desteklenmemektedir. Bu durum, sürdürülebilirlikle ilgili kavramların diğer 
zorunlu-seçmeli derslerle ilişkilendirilmediğini ve öğrencilerin bu anlamda tasarım sürecine katkı sunacak şekilde düzenlenmediğini göstermektedir. Sürdürülebilirlikle ilgili iç mekanı etkileyen kriterlerin özellikle tasarım süreciyle uygulamalı eğitime dayanan derslerle ilişkilendirilmesi konunun pekiştirilmesi açısından faydalı olacaktır. Ayrıca bu kriterlerin zorunlu derslerle ilişkilendirilmesi; sürdürülebilirlik gibi hepimizin geleceğini ilgilendiren bir konuda en azından farkındalık oluşturmak amacıyla tüm öğrencilerin faydalanabileceği bir şekilde planlanabilir.

Hacettepe Üniversitesi İç Mimarlık ve Çevre Tasarımı lisans programında yer alan derslerin sürdürülebilirlik kapsamında incelenmesi ile ilgili detaylar Tablo 4'te verilmiştir. Bilgi paketlerine göre HÜ İç Mimarlık lisans programında yer alan "İç Mekan Tasarımı” dersleri; öğrencilerin iç mekanla ilgili çeşitli problemleri çözme yolunda, çevre dokusu ve mevcut yapı niteliklerini göz önüne alarak tüm veriler ışı̆̆ında renk, doku ve malzeme kararlarına kadar detayların tasarlanması amaçlanmaktadır. Bilgi paketindeki ifadelerden dersin; malzeme seçimi, 1sıtma sistemleri, doğal ve yapay aydınlatma alternatifleri gibi iç mekan konforu ile ilişkili konuları kapsadığı görülmektedir [10]. Fakat konuların sürdürülebilirlik çerçevesinde iç mekanı etkileyen kriterlerden "malzeme ve sağlık-konfor" kıstaslarını karşıladığı söylenemez. Bilgi paketlerinde yer alan öğrenme çıktıları ve haftalık detaylı ders içeriklerinden bu kriterlerin ancak kısmen desteklendiği ifade edilebilir. Diğer kriterler desteklenmemektedir. "Mobilya Tasarımı, Mobilya Yapım Yön. ve Teknikleri” dersleri, bilgi paketlerine göre hiçbir kriteri desteklememektedir.

Tablo 4. HÜ İç Mimarlık ve Çevre Tasarımı lisans programında sürdürülebilirlikle ilişki kurulabilecek ders bilgi paketlerinin [10] incelenmesi

\begin{tabular}{|c|c|c|c|c|c|c|c|}
\hline \multicolumn{2}{|r|}{$\begin{array}{c}\text { Hacettepe Üniversitesi } \\
\text { İç Mimarlık ve Çevre Tasarımı Lisans Programı }\end{array}$} & 浔 & 言 & 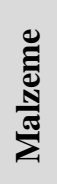 & 光总 & $\overrightarrow{\tilde{H}}$ & 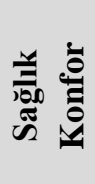 \\
\hline \multirow{5}{*}{ 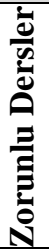 } & İç Mekan Tasarımı I, II, III, IV, V, VI & $\mathrm{X}$ & $\mathrm{X}$ & $\sim$ & $\mathrm{X}$ & $\mathrm{X}$ & $\sim$ \\
\hline & Mobilya Tasarımı I, II & $\mathrm{X}$ & $\mathrm{X}$ & $\mathrm{X}$ & $\mathrm{X}$ & $\mathrm{X}$ & $\mathrm{X}$ \\
\hline & Mobilya Yapım Yöntem ve Teknikleri I, II, & $\mathrm{X}$ & $\mathrm{X}$ & $\mathrm{X}$ & $\mathrm{X}$ & $\mathrm{X}$ & $\mathrm{X}$ \\
\hline & İç Mekanda Yapım ve Malzeme I, II & $\mathrm{X}$ & $\mathrm{X}$ & $\mathrm{X}$ & $\mathrm{X}$ & $\mathrm{X}$ & $\mathrm{X}$ \\
\hline & İç Mekanda Çevre Kontrol Sistemleri & $\mathrm{X}$ & $\mathrm{X}$ & $\mathrm{X}$ & $\sim$ & $\checkmark$ & $\checkmark$ \\
\hline \multirow{5}{*}{ 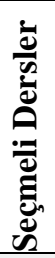 } & İç Mekanda Işık Renk ve Doku & $\mathrm{X}$ & $\mathrm{X}$ & $\mathrm{X}$ & $\mathrm{X}$ & $\mathrm{X}$ & $\sim$ \\
\hline & Teknoloji ve Mekan & $\mathrm{X}$ & $\mathrm{X}$ & $\mathrm{X}$ & $\mathrm{X}$ & $\mathrm{X}$ & $\sim$ \\
\hline & Çevre ve Etik & $\mathrm{X}$ & $\sim$ & $\mathrm{X}$ & $\mathrm{X}$ & $\mathrm{X}$ & $\mathrm{X}$ \\
\hline & Sürdürülebilir Tasarım & $\checkmark$ & $\sim$ & $\checkmark$ & $\sim$ & $\sim$ & $\checkmark$ \\
\hline & Sürdürülebilir Kent ve Mekan Tasarımı & $\sim$ & $\sim$ & $\sqrt{ }$ & $\sim$ & $\sim$ & $\sim$ \\
\hline \multicolumn{8}{|c|}{$\sqrt{ }$ : Destekleniyor, $\quad$ : Kismen Destekleniyor, X: Desteklenmiyor } \\
\hline
\end{tabular}

HÜ İç Mimarlık lisans programındaki "İç Mekanda Yapım ve Malzeme” dersleri de bilgi paketlerine göre söz konusu kriterlerin hiç birini desteklememektedir. Fakat "İç Mekanda Çevre Kontrol Sistemleri” dersinin kapsamı dahilinde "Su ve Sağlık-Konfor” kriterlerini desteklediği görülmüştür. Bu derste kısaca; yapıda insan sağlığının korunabilmesi için gerekli temiz içme-kullanma suyunun temini, kirli ve pis suların yapıdan uzaklaştırılması için gerekli tesisin planlanması-kurulması aynı zamanda yapı için gerekli olan yapı 1sıtma-soğutma-aydınlatma tesislerinin Türk Standartları ve Uluslararası standartlara göre projelendirilmesi yönünde bilgiler aktarmak amaçlanmıştır.

Seçmeli derslerden "İç Mekanda Işık Renk ve Doku” dersinde doğal aydınlatma - gün 1şı̆̆ı kullanımı ve 1şık düzeyleri konuları yer almaktadır. "Teknoloji ve Mekan” dersinde İç mekanda fiziksel konfor seviyesini sağlamak için kullanılan çağdaş sistemler ve eko-tek çözümler, ayrıca gün ışığının etkili kullanımı konu alınmıştır. Bu derslerin "Sağlık-Konfor" kriterini kısmen desteklediği söylenebilir. "Çevre ve Etik” dersi; tasarım odaklı çözümlerde çevre kirlenmesi, türleri ve nedenleri gibi konularda bilinç ve farkındalık oluşturmayı amaçlamaktadır. Fakat ekipman kullanımı, atık yönetimi veya azot oksit salınımı gibi konulara yer verilmemiştir, dolaysıyla "Kirlilik" kriterini ancak kısmen desteklediği söylenebilir.

HÜ İç Mimarlık lisans programında sürdürülebilirliği doğrudan konu alan iki farklı seçmeli dersin yer alıyor olması konuya verilen önemi göstermektedir. Fakat zorunlu bir ders dahilinde bu konuların işlenmesi programda eğitim gören tüm öğrencilerin konuyla ilgili bilinç ve farkındalığa sahip olması açısında daha yararlı olacaktır. Ayrıca 
sürdürülebilirlikle ilgili edinilen teorik bilgilerin özellikle uygulamalı diğer derslerle pekiştirilmesi amaca çok daha uygun olacaktır.

Eskişehir Teknik Üniversitesi İç Mimarlık lisans programında yer alan derslerin sürdürülebilirlik kapsamında incelenmesi ile ilgili detaylar Tablo 5'te verilmiştir.

Tablo 5. Eskişehir Tek. Üni. İç Mimarlık lisans programında sürdürülebilirlikle ilişki kurulabilecek ders bilgi paketlerinin [11] incelenmesi

\begin{tabular}{|c|c|c|c|c|c|c|c|}
\hline & $\begin{array}{c}\text { Eskişehir Teknik Üniversitesi } \\
\text { İç Mimarlık Lisans Programı } \\
\text { DERS ADI }\end{array}$ & $\begin{array}{l}:=\frac{1}{\grave{\Xi}} \\
\text { : }\end{array}$ & 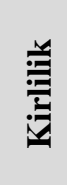 & 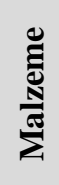 & 兑薯 & $\bar{\omega}$ & 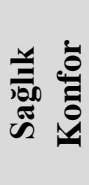 \\
\hline$\dot{0}$ & İç Mimari Proje I, II, III, IV, V, VI & $\mathrm{X}$ & $\mathrm{X}$ & $\sim$ & $\mathrm{X}$ & $\mathrm{X}$ & $\sim$ \\
\hline$\Xi$ & Mobilya I, II & $\mathrm{X}$ & $\mathrm{X}$ & $\mathrm{X}$ & $\mathrm{X}$ & $\mathrm{X}$ & $\mathrm{X}$ \\
\hline$E$ & Malzeme & $\mathrm{X}$ & $\mathrm{X}$ & $\sim$ & $\mathrm{X}$ & $\mathrm{X}$ & $\mathrm{X}$ \\
\hline$\stackrel{\hat{N}}{2}$ & Fiziksel Çevre Kontrolü I, II & $\mathrm{X}$ & $\mathrm{X}$ & $\mathrm{X}$ & $\mathrm{X}$ & $\mathrm{X}$ & $\checkmark$ \\
\hline$\dot{\theta}$ & Yapıda Taşıyıcı Sistemler & $\mathrm{X}$ & $\mathrm{X}$ & $\sim$ & $\mathrm{X}$ & $\mathrm{X}$ & $\mathrm{X}$ \\
\hline $\bar{\Xi}$ & Mobilya Konstrüksiyon & $\mathrm{X}$ & $\mathrm{X}$ & $\sim$ & $\mathrm{X}$ & $\mathrm{X}$ & $\mathrm{X}$ \\
\hline 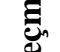 & Aydınlatma Tasarımı & $\mathrm{X}$ & $\mathrm{X}$ & $\mathrm{X}$ & $\mathrm{X}$ & $\mathrm{X}$ & $\mathrm{X}$ \\
\hline מั & Farklı Mekanlarda Aydınlatma İlkeleri & $\mathrm{X}$ & $\mathrm{X}$ & $\mathrm{X}$ & $\mathrm{X}$ & $\mathrm{X}$ & $\mathrm{X}$ \\
\hline & $\checkmark$ : Destekleniyor, $\sim:$ Kısme & niyo & $\mathrm{X}: \mathrm{I}$ & len & & & \\
\hline
\end{tabular}

"İç Mimari Proje, Mobilya ve Malzeme" dersleri bilgi paketlerine göre söz konusu kriterlerin hiçbirini doğrudan desteklememektedir. Fakat "Malzeme ve Sağlkk-konfor" kriterlerinin kısmen desteklendiği ifade edilebilir [11]. "Fiziksel Çevre Kontrolü” dersi; doğal aydınlatma tasarımı, gün ışığı kullanımı, ışık düzeyleri, ses gürültü konforu, akustik gibi konuları içermektedir. Bu konuların ele alınış biçimi "Sağlık-Konfor” kriterini destekleyecek şekilde sürdürülebilir tasarım çözümlerini karşılamaktadır. Diğer kriterlerle ilişki kurulmamıştır.

Seçmeli derslerden "Yapıda Taşıyıcı Sistemler, Mobilya Konstrüksiyon, Aydınlatma Tasarımı, Farklı Mekanlarda Aydınlatma İlkeleri” gibi dersler sürdürülebilirlikle herhangi bir şekilde ilişkilendirilmememiştir. Bilgi paketlerinde ifade edilen; işleve uygun malzeme seçimi çerçevesinde malzeme çeşitleri-özellikleri ve malzeme sağlamlığı gibi konuların kısmen bazı kıstaslara karşılık geldiği düşünülebilir.

Sonuç olarak Eskişehir Tek. Üni. İç Mimarlık lisans programında sürdürülebilirliği doğrudan konu alan zorunlu ya da seçmeli herhangi bir dersin yer almadığı ve mevcut derslerde sürdürülebilirlikle ilgili iç mekanı etkileyen kriterlerin yeterince desteklenmediği görülmektedir.

İstanbul Kültür Üniversitesi İç Mimarlık ve Çevre Tasarımı lisans programında yer alan derslerin sürdürülebilirlik kapsamında incelenmesi ile ilgili detaylar Tablo 6'da verilmiştir. 
Tablo 6. İKÜ İç Mimarlık ve Çevre Tasarımı lisans programında sürdürülebilirlikle ilişki kurulabilecek ders bilgi paketlerinin [12] incelenmesi

\begin{tabular}{|c|c|c|c|c|c|c|c|}
\hline \multicolumn{2}{|r|}{$\begin{array}{c}\text { İstanbul Kültür Üniversitesi } \\
\text { İç Mimarlık ve Çevre Tasarımı Lisans Programı } \\
\text { DERS ADI }\end{array}$} & 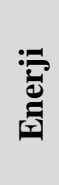 & 产 & 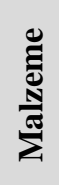 & 葛 & $\bar{\omega}$ & 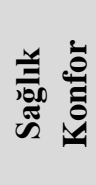 \\
\hline \multirow{7}{*}{ 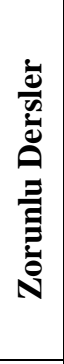 } & İç Mimarlık Proje III, IV, V, VI, VII ve Bitirme Pro. & $\mathrm{X}$ & $\mathrm{X}$ & $\sim$ & $\mathrm{X}$ & $\mathrm{X}$ & $\checkmark$ \\
\hline & İç Mekan ve Mobilya & $\mathrm{X}$ & $\mathrm{X}$ & $\mathrm{X}$ & $\mathrm{X}$ & $\mathrm{X}$ & $\mathrm{X}$ \\
\hline & Donatı Tasarımı & $\mathrm{X}$ & $\mathrm{X}$ & $\mathrm{X}$ & $\mathrm{X}$ & $\mathrm{X}$ & $\mathrm{X}$ \\
\hline & Yap1 Bilgisi ve Malzeme I, II & $\mathrm{X}$ & $\mathrm{X}$ & $\sim$ & $\mathrm{X}$ & $\mathrm{X}$ & $\sim$ \\
\hline & Yap1 ve Tesisat & $\mathrm{X}$ & $\mathrm{X}$ & $\mathrm{X}$ & $\mathrm{X}$ & $\checkmark$ & $\checkmark$ \\
\hline & Aydınlatma & $\sim$ & $\mathrm{X}$ & $\mathrm{X}$ & $\mathrm{X}$ & $\mathrm{X}$ & $\checkmark$ \\
\hline & Akustik & $\mathrm{X}$ & $\mathrm{X}$ & $\mathrm{X}$ & $\mathrm{X}$ & $\mathrm{X}$ & $\checkmark$ \\
\hline \multirow{5}{*}{ 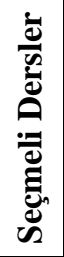 } & Isitma ve Havalandirma & $\mathrm{X}$ & $\mathrm{X}$ & $\mathrm{X}$ & $\mathrm{X}$ & $\mathrm{X}$ & $\checkmark$ \\
\hline & Mutfak ve Banyo Tasarımı & $\mathrm{X}$ & $\mathrm{X}$ & $\mathrm{X}$ & $\mathrm{X}$ & $\mathrm{X}$ & $\sim$ \\
\hline & Mobilya Tasarımı & $\mathrm{X}$ & $\mathrm{X}$ & $\mathrm{X}$ & $\mathrm{X}$ & $\mathrm{X}$ & $\mathrm{X}$ \\
\hline & İç Mimarlıkta Sürdürülebilir Tasarım & $\checkmark$ & $\sim$ & $\sim$ & $\sim$ & $\sim$ & $\sim$ \\
\hline & Enerji Etkin Tasarım Yaklaşımı & $\checkmark$ & $\sim$ & $\sim$ & $\sim$ & $\sim$ & $\sim$ \\
\hline \multicolumn{8}{|c|}{$\checkmark$ : Destekleniyor, $\quad \sim$ : Kısmen Destekleniyor, X: Desteklenmiyor } \\
\hline
\end{tabular}

İKÜ İç Mimarlık Proje derslerinin "Sağlık-Konfor" kriterini desteklediği görülmektedir. Bilgi paketine göre dersin içeriği: "aydınlatma, akustik, ısıl konfor ve iç mekan hava kalitesi, sıhhi tesisat ilkelerini insan sağlığı, güvenliği ve konforu” gibi konuları kapsamaktadır. İnsan sağlığı ve yaşam kalitesine katkı sağlayacak projeler geliştirebilmek amaçlanmıştır [12]. "İç Mekan ve Mobilya" ve "Donatı Tasarımı" dersleri bilgi paketlerine göre sürdürülebilirlik kavramıyla hiçbir şekilde ilişkilendirilmemiştir. "Yapı Bilgisi ve Malzeme" dersinin bilgi paketinde öğrenme çıktısı olarak "sürdürülebilir yapı ve yapım ilişkilerine kurabilme" ifadesi yer alsa da dersin detaylı içeriği incelendiğinde aslında söz konusu kriterlerin desteklenmediği görülmektedir. Öte yandan "Yapı ve Tesisat" dersi "Su ve SağlıkKonfor” kriterini desteklemektedir. Bu dersin içeriği bilgi paketinde şu şekilde özetlenmiştir: “...Yapma çevrenin tasarlanma sürecince binaya temiz su sağlama ve atık su uzaklaştırma gibi sağlık donatımı sistemlerinin tanıtılması; aydınlatma, akustik, ısıl konfor ve sıhhi tesisat, iç mekan hava kalitesi ilkelerini insan sağlığı, güvenliği ve konforuna uygun olarak geliştirebilmesi..." [13].

"Aydınlatma, Akustik ve Isıtma Havalandırma" dersleri de yine sağlık-konfor kriterini destekleyecek şekilde ifade edilmiştir. Fakat seçmeli derslerden "Mutfak ve Banyo Tasarımı, Mobilya Tasarımı" dersleri sürdürülebilirlikle ilişkilendirilmemiştir.

İKÜ İç Mimarlık lisans programında doğrudan sürdürülebilirliği konu alan iki seçmeli dersin yer aldığı fakat bu derslerin ikisinin de "Enerji”" kriterine odaklandığı tespit edilmiştir. Bu derslerin öğrenme çıktılarında "Yeşil, ekolojik, sürdürebilirlik ve çevreye duyarlı tasarım kavramları hakkında bilgi edinme ve yenilenebilir enerji kaynaklarını kullanma becerilerini geliştirme" ifadeleri yer almaktadır. Tablo 6 genel anlamda değerlendirildiğinde LEED ve BREEAM sertifikasyon sistemlerine ait iç mekanı etkileyen kriterlerden "Kirlilik, Malzeme ve Atık Yönetimi” başlıklarının yeterince desteklenmediği görülmektedir. Sürdürülebilirliğin eğitim sisteminde daha geniş bir şekilde yer alması için bu kriterlere odaklanmış farklı seçmeli dersler oluşturulabileceği gibi, mevcut dersler içinde de ilgili kıstaslara değinilebilir. Ayrıca sürdürülebilirlikle ilişkili kavramlar uygulama çalışmalarıyla (çözüm bekleyen birer problem olarak) tasarım sürecine dahil edilebilir. Böylece sürdürülebilirlik kapsamında ele alınabilecek iç mekanı etkileyen tüm kriterler eğitim sistemine dahil edilmiş olur ve öğrencilerin konuyla ilgili bilinç düzeyi artar.

İstanbul Teknik Üniversitesi İç Mimarlık lisans programında yer alan derslerin sürdürülebilirlik kapsamında incelenmesi ile ilgili detaylar Tablo 7'de verilmiştir. 
Tablo 7. İTÜ İç Mimarlık lisans programında sürdürülebilirlikle ilişki kurulabilecek ders bilgi paketlerinin [13] incelenmesi

\begin{tabular}{|c|c|c|c|c|c|c|c|}
\hline & $\begin{array}{c}\text { İstanbul Teknik Üniversitesi } \\
\text { İç Mimarlık Lisans Programı } \\
\text { DERS ADI }\end{array}$ & 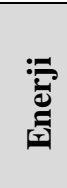 & 䞸 & 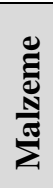 & 兰薯 & $\bar{~}$ & 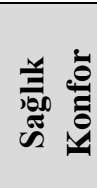 \\
\hline & Iç Mimarlık Projesi I, II, III, IV, V ve Diploma Proj. & $\mathrm{X}$ & $\mathrm{X}$ & $\sim$ & $\mathrm{X}$ & $\mathrm{X}$ & $\sim$ \\
\hline a & $\begin{array}{l}\text { Space and Furniture } \\
\end{array}$ & $\mathrm{X}$ & $\mathrm{X}$ & $\mathrm{X}$ & $\mathrm{X}$ & $\mathrm{X}$ & $\mathrm{X}$ \\
\hline $\bar{E}$ & Yap1 Bilgisine Giriş & $\sim$ & $\mathrm{X}$ & $\sim$ & $\mathrm{X}$ & $\mathrm{X}$ & $\sim$ \\
\hline N & Yap1 Malzemesi I, II & $\mathrm{X}$ & $\mathrm{X}$ & $\checkmark$ & $\mathrm{X}$ & $\mathrm{X}$ & $\sim$ \\
\hline$\dot{\varphi}$ & Building Biology and Ecology & $\mathrm{X}$ & $\mathrm{X}$ & $\sim$ & $\mathrm{X}$ & $\mathrm{X}$ & $\checkmark$ \\
\hline 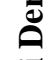 & Bina, İklim, Enerji İlişkileri & $\checkmark$ & $\mathrm{X}$ & $\mathrm{X}$ & $\mathrm{X}$ & $\mathrm{X}$ & $\mathrm{X}$ \\
\hline 茪 & Yapıda Malzeme Seçimi & $\mathrm{X}$ & $\mathrm{X}$ & $\checkmark$ & $\mathrm{X}$ & $\mathrm{X}$ & $\sim$ \\
\hline पूँ & Sustainability in Interior Architecture & $\checkmark$ & $\checkmark$ & $\checkmark$ & $\checkmark$ & $\checkmark$ & $\checkmark$ \\
\hline
\end{tabular}

İTÜ İç Mimarlık lisans programı bünyesindeki "Iç Mimarlık Projesi" ve "Space and Furniture" dersleri sürdürülebirlikle ve iç mekanı etkileyen kriterlerle ilişkilendirilmemiştir. Fakat "Yapı Bilgisine Giriş" dersinin bilgi paketinde yer alan öğrenme çıtıllarında sürdürülebilirlik kavramına yer verilmiştir ve şu şekilde açıklanmıştır: "Doğal ve yapma kaynaklar, kullanıcılar için sağlıklı çevre oluşturma ve bina yapımı ve kullanımının gelecek nesillere karbondoğal tasarım, biyolojik-iklimsel tasarım ve enerji korunumu gibi konularda az etki bırakması için tasarımları optimizasyon, korunum ve yeniden kullanıma uygun şekilde ele alma..." [14]. Dersin bu bağlamda "Enerji, Malzeme ve Sağlık-Konfor" başlıklarını kısmen desteklediği ifade edilebilir. "Yapı Malzemesi" dersi bilgi paketine göre kısaca yapı-malzeme-tasarım ilişkisi kapsamındadır. Ders konusu; sürdürülebilir kaynak kullanımı çerçevesinde ele alınmıştır ve malzeme özellikleri-performans kriterlerini içermektedir.

Seçmeli derslerden "Yapı Biyolojisi ve Ekoloji (Building Biology and Ecology)" dersi kısaca "İnsan ve doğal çevre sağlı̆̆ı, insan-yapı-çevre ilişkisi; ekoloji konularını kapsamaktadır. Ders içeriği: yapı biyolojisi, ilkeleri ve insandoğa sağlığı üzerindeki etkileri; yapı biyolojisinin belirleyiciliğinde iç mekan analizleri ve ölçümleri; doğru malzeme seçimi ve tasarımda ekolojik sürdürülebilirlik şeklinde özetlenebilir [15]. Bilgi paketine göre bu ders daha çok "SağlıkKonfor" kriterini destekleycek nitekliktedir.

"Bina, İklim, Enerji İlişkileri” dersi sürdürülebilirlikle doğrudan ilişkilendirilip "Enerji” kriteri üzerine odaklanmıştır. Dersin içeriği şu şekilde ifade edilmiştir: "Binalarda enerji kullanımı, binalarda enerji kullanımına etki eden tasarım parametreleri; alternatif enerji kaynakları, iklimle dengeli binalar, bina performansının bir bina simülasyon programı ile değerlendirilmesi." [16].

"Yapıda Malzeme Seçimi" dersi de yine sürdürülebilir kaynak kullanımı çerçevesinde ele alınmıştır. Ders, yapıda kullanılacak malzemelerin performans kriterleri kapsamında değerlendirilmesi ile ilgili konuları içermektedir. Bu derste 1s1 tutucu, buhar kesici, su yalıtıcı ve ses yutucu malzemeler, su ve buhar yalıtımı hesap ve ilkeleri dahilinde konfor koşulları işlenmektedir.

İTÜ İç Mimarlık lisans programındaki "İç Mimarlıkta Sürdürülebilirlik (Sustainability in Interior Architecture)" dersi bilgi paketine göre LEED ve BREEAM sertifikasyon sistemlerine ait iç mekanı etkileyen kriterlerin hepsini karşılayacak şekildedir. Bununla birlikte yukarıda görüldüğü gibi sürdürülebilirlik kavramı başka dersler tarafindan da oldukça desteklenmektedir. Sistemin bu yönüyle diğer kurumlar için örnek teşkil edebileceği düşünülebilir. Yine de sürdürülebilirlik kavramının herhangi bir derste proje-tasarım süreciyle ilişkilendirilmemiş yani uygulama çalışmalarıyla yeterince desteklenmemiş olduğu görülmektedir. Teorik bilgilerin çeşitli uygulamalarla pekiştirilmesi yararlı olacaktır.

Çalışma grubundaki tüm kurumlara ait bulgular göz önünde bulunrularak, derslerin en fazla "Sağlık-Konfor" kriteriyle iliş̧ilendirildiği söylenebilir. İkinci sırada "Malzeme" üçüncü sırada da "Enerji" yer alırken sıralama "Su, Atık Yönetimi ve Kirlilik" şeklinde devam etmektedir. Bu kapsamda verilecek eğitimin tüm kriterleri karşılayacak şekilde olması, öğrencilerin sürdürülebilirlik, çevre ve ekoloji gibi konularda bilgilenmesi ve sadece teorik değil aynı zamanda uygulamaya yönelik bilgiler edinmesi gerekmektedir. Genç tasarımcı adaylarının sürdürülebilirlikle ilgili kişisel duyarlılığı ve farkındalığı geliştirmesi oldukça önemlidir. Öğrencilerin eğitim sürecinde doğal ve yenilenebilir kaynak 
kullanımına yönelmeleri, geri dönüşüm ve yeniden kullanımı tasarım kararlarında etken olarak ele alma sorumluluğunu üstlenmeleri mesleki hayatlarında da tercihlerine yön verecektir. Ayrıca yapı elemanlarının ve sistemlerinin insan performansına ya da sağlığına etkilerini ve iç mekan kalitesi bağlamında gereksinim duyulan fizyolojik özelliklerini öğrenmeleri iç mekan tasarımcısı olarak gelişimleri açısından mecburidir. Bu noktada çeşitli sürdürülebilir tasarım sertifika programları ve değerlendirme araçları ile ilgili bilgiler edinmeleri de sürdürülebilirlik kavramını yorumlayarak iç mekan tasarımına aktarma ve ifade etme becerilerini geliştiremeye katkı sağlayacaktır.

\section{Tartıșma ve Sonuç}

Ülkemiz üniversiteleri iç mimarlık bölümleri üzerinden sürdürülebilirlik kavramının iç mimarlık eğitiminde dersler üzerindeki etkileri irdelenen bu çalışma ile elde edilen sonuçlar ve sonuçlara bağlı olarak geliştirilen öneriler şu şekildedir;

- $\quad$ İç mimarlık eğitiminin ağırlıklı dersi olarak kabul edilebilecek proje stüdyo derslerinde malzeme ile sağlık ve konfor konularında sürdürülebilirliğin kısmen etkili olduğu görülmüştür. Enerji, atık yönetimi ve kirlilik konuları ise bu ders kapsamında ele alınmamaktadır. Özellikle iç mekanda iklimlendirme, aydınlatma tasarımı gibi konuların stüdyo derslerinde sürdürülebilirlik ile birlikte ele alınması gerekmektedir.

- $\quad$ Mobilya tasarımı üzerine kurgulanan derslerde sürdürülebilirlik ile ilgili hiçbir hususun dikkate alınmadığı ve üzerinde durulmadığı gözlemlenmektedir. Mobilya tasarımlarında özellikle malzeme türü, kullanımları ve kullanılan malzeme miktarı konusunun üzerinde durulması toksik madde üretimi, Co2 salınımları, yanlış malzeme seçimleri ile yaşam döngüsü kısa mobilya tasarımlarının oluşturulması gibi çevresel açıdan olumsuz etkilerin azaltılmasında tasarım öğrencilerinin bilinçlendirilmesine katkıda bulunacaktır.

- Yapı anabilim dalı ile ilgili derslerin kapsamında sürdürülebilirlik konusunun yeterince işlenmediği görülmektedir. Malzeme alanını konu alan derslerde sağlık ve konfor konuları; 1sıtma, havalandırma ve tesisat derslerinde enerji, su gibi konuların üzerinde daha fazla durulmalıdır.

- $\quad$ Açılan seçmeli dersler ile sürdürülebilirliğin iç mekanla ilişkisi üzerinde daha fazla durulması gerektiği tespit edilmiştir. Özellikle iç mekanların daha sürdürülebilir hale getirilmesine yönelik dikkat edilmesi gereken hususlar bu dersler kapsamında her yönü ile detaylı bir biçimde irdelenmelidir.

Sonuç olarak iç mimarlık alanında sürdürülebilirlik konusunun eğitim aşamasında öğrencilerin eğitiminin bir parçası haline getirilmesi; gelecek nesillere daha yaşanılabilir bir çevre bırakılması açısından oldukça önemlidir. Bu nedenle iç mimarlık eğitimi düzenlenirken sürdürülebilirlik eğitimin bir parçası haline getirilmeli ve tasarımcı adaylarının meslek yaşantılarında mekan tasarımlarında sürdürülebilirliği mekan gereksinimlerinden bir tanesi olarak düşünmeleri sağlanmalıdır.

\section{Kaynaklar}

[1] Ashford, P. (1998), Assessment Of Potential For The Saving Of Carbon Dioxide

[2] Ashford, P. (1999), The Cost Implications of Energy Efficiency Measures in the Reduction of Carbon Dioxide Emissions From European Building Stock. Bristol: Caleb Management Services.

[3] Özmehmet, Ö. G. E. (2007). Avrupa ve Türkiye'deki Sürdürülebilir Mimarlık Anlayışına Eleştirel Bir Bakış. Journal Of Yaşar University, 2(7), 809-826.

[4] Sipahi, S., 2013. Otel iç mekânlarında enerji kullanımı açısından sürdürülebilirlik: Antalya örneği, Yüksek Lisans Tezi, Karadeniz Teknik Üniversitesi. Fen Bilimleri Enstitüsü Enstitüsü, Trabzon.

[5] Sur, H., 2012, Çevre Dostu Yeşil Binalar, Yeşil Binalar Referans Rehberi 2012, İstanbul.

[6] Şimşek, E., P., 2012, Sürdürülebilirlik Bağlamında Yeşil Bina Olma Kriterleri “Kağıthane Ofispark Projesi Örneği”, Yüksek Lisans Tezi, İstanbul Teknik Üniversitesi Fen Bilimleri Enstitüsü, İstanbul. 
[7] Torun, A. ve Yalçınkaya Ş., 2016. Bilgi Okuryazarlığının İç Mimarlık Eğitim Sistemindeki Yeri. International Conference On Quality In Higher Edutation, Kasım, Proceeding Book, Sakarya, 110-123

[8] Torun, A., 2017. İç Mimarlık Lisans Eğitiminde Bilgi Okuryazarlığının Çok Yönlü Analizi ve Bir Ders Önerisi, Yüksek Lisans Tezi, Karadeniz Teknik Üniversitesi. Fen Bilimleri Enstitüsü Enstitüsü, Trabzon.

[9] http://lp.marmara.edu.tr/ProgramTanitim/guzel-sanatlar-fakultesi/ic-mimarlik-44-51-0, Marmara Üniversitesi Güzel Sanatlar Fakültesi İç Mimarlık Bölümü Bilgi Paketleri. 04 Nisan 2019.

[10] http://akts.hacettepe.edu.tr/ders_listesi.php?prg_ref=PRGRAM_0000000000000000000000040\&birim_ kod=465\&submenuheader=2\&prg_kod=465, Hacettepe Üniversitesi Güzel Sanatlar Fakültesi İç Mimarlık ve Çevre Tasarımı Bölümü Bilgi Paketleri. 05 Nisan 2019.

[11] https://www.eskisehir.edu.tr/akademik/fakulteler/197/ic-mimarlik-bolumu/dersler, Eskişehir Teknik Üniversitesi Mimarlık ve Tasarım Fakültesi İç Mimarlık Bölümü Bilgi Paketleri. 06 Nisan 2019.

[12] https://legacy.iku.edu.tr/TR/ects_bolum.php? $\mathrm{m}=1 \& \mathrm{p}=16 \& \mathrm{f}=5 \& \mathrm{r}=0 \&$ ects $=$ ders, İstanbul Kültür Üniversitesi Sanat ve Tasarım Fakültesi İç Mimarlık ve Çevre Tasarımı Bölümü Bilgi Paketleri. 07 Nisan 2019.

[13] http://www.sis.itu.edu.tr/tr/dersplan/plan/ICM/201810.html, İstanbul Teknik Üniversitesi Mimarlık Fakültesi İç Mimarlık Bölümü Bilgi Paketleri. 08 Nisan 2019.

[14] http://ssb.sis.itu.edu.tr:9000/pls/PROD/itu_icerik.p_download?file=MIM162, İTÜ Mimarlık Fakültesi İç Mimarlık Bölümü “Yapı Bilgisine Giriş” Dersi Bilgi Paketi. 09 Nisan 2019.

[15] http://ssb.sis.itu.edu.tr:9000/pls/PROD/itu_icerik.p_download?file=ICM453E, İTÜ Mimarlık Fakültesi İç Mimarlık Bölümü “Building Biology and Ecology” Dersi Bilgi Paketi. 09 Nisan 2019.

[16] http://ssb.sis.itu.edu.tr:9000/pls/PROD/itu_icerik.p_download?file=MIM346, İTÜ Mimarlık Fakültesi İç Mimarlık Bölümü “Bina, İklim, Enerji İlişkileri” Dersi Bilgi Paketi. 09 Nisan 2019..

\section{Extended Abstract}

\section{Introduction}

The mass production which started with industrial revolution was used in different fields. One of these areas is the building sector. Industrialization in the construction sector has led to differentiation in construction techniques and material use.

These developments in the building sector have influenced the design education and hence the internal architecture education. interior architecture education differs with the developing technology. Different techniques such as construction techniques, materials, design understanding and computer technology have been included in interior architecture education over time.

Industrialization and mass production; excessive resource consumption and adverse environmental impacts. For this reason, the environmentalist views that started to be revealed at the end of the 1960s; In the 1980s, it took part in the international platforms with the concept of sustainability.

Today, the concept of sustainability, which has a place in every field of industry, is also a remarkable issue in the construction sector. The importance of the concept of sustainability for the building sector is better understood, 
especially considering the environmental impacts of the building life cycle. When sustainability is discussed in buildings, sustainability in building interiors; It is seen that the building has an important place in the surrounding and building peel. However, the extent to which these changes are reflected in interior architecture education is a matter of debate. The subjects such as design ideas, materials, construction techniques are added to interior architecture education in time; The question of how much sustainability is included is a question mark for our country and the whole world.

\section{Method}

In this study, a study on the inclusion of the concept of sustainability into the internal architecture undergraduate programs was carried out. The sample group with different perspectives in educational institutions in Turkey are taken. For this reason, 5 different programs from internal architecture undergraduate programs in our country have been determined as a sample group. The courses of the internal architecture undergraduate programs in the sample group were examined through the course information packages. The discussion consists of 2 stages. In the first stage, the aim and content topics included in the course information packages were examined; Turkish language courses such as Turkish language, English as well as technical drawing and basic art education such as basic art education were excluded from the scope. In the second stage, the course learning outcomes and weekly detailed course contents were examined and the topics related to whether the courses were related to sustainability concept and how they were related were discussed. For the analysis of this association, the criteria affecting the interior of LEED and BREEAM certification systems were used.

In the study, a study was carried out on the reflection of the concept of sustainability to the courses in the internal architecture undergraduate programs. In this way, the institutions that educate the future designer candidates are examined and the place of sustainability in interior architecture vocational education is examined. sample of the study consists of five educational institutions in Turkey, having different perspectives on Interior Architecture training. These institutions:

- Marmara University, Faculty of Fine Arts, Department of Interior Architecture,

- Hacettepe University Faculty of Fine Arts Department of Interior Architecture and Environmental Design,

- Eskişehir Technical University (formerly Anadolu University) Faculty of Architecture and Design Department of Interior Architecture,

- Istanbul Kültür University Faculty of Art and Design Department of Interior Architecture and Environmental Design

- Istanbul Technical University Faculty of Architecture Department of Interior Architecture

The courses of the internal architecture undergraduate programs in the sample group were examined through the course information packages. The process consists of two stages:

In the first stage, the topics of "purpose“ and yer content in the course packages were examined; Sustainability concept can not be established with the exception of Turkish language, English courses, such as technical courses, basic art education, such as basic education courses are excluded. At this stage, elective courses which directly related to sustainability were reached. These courses, which are directly related to sustainability, are examined in accordance with the criteria described in Table 1, taking into account the ler learning outcomes an and 1 weekly detailed contents "in the information packages.

In the second stage, öğrenme course learning outcomes ders and kur weekly detailed course contents "of the other courses that can be related to the concept of sustainability were examined. Whether or not the courses are related to the concept of sustainability or how they are associated are discussed in the above mentioned criteria. 


\section{Results and Discussion}

Consequently, as a result of research carried out on the sample stage of university education in sustainability issues in interior design education in Turkey was determined to be emphasized enough. Making sustainability a part of the education of students in the field of education in the field of education; it is very important for the future generations to leave a more livable environment. For this reason, sustainability should be made a part of education while organizing interior architecture education and it should be ensured that designer candidates consider sustainability in space design as one of the space requirements. 